Boise State University

ScholarWorks

Psychological Sciences Faculty Publications and

Presentations

Department of Psychological Science

$12-1-2012$

\title{
Interpersonal Identity Formation in Conversations with Close Friends About Dating Relationships
}

Elizabeth M. Morgan

Boise State University

Neill Korobov

University of West Georgia

NOTICE: This is the author's version of a work accepted for publication by Elsevier. Changes resulting from the publishing process, including peer review, editing, corrections, structural formatting and other quality control mechanisms, may not be reflected in this document. Changes may have been made to this work since it was submitted for publication. The definitive version has been published in Journal of Adolescence, 2011. DOI: 10.1016/j.adolescence.2011.09.005 
NOTICE: This is the author's version of a work accepted for publication by Elsevier. Changes resulting from the publishing process,

including peer review, editing, corrections, structural formatting and other quality control mechanisms, may not be reflected in this document. Changes may have been made to this work since it was submitted for publication. The definitive version has been published in Journal of Adolescence, 2011. DOI: 10.1016/j.adolescence.2011.09.005

\title{
Interpersonal Identity Formation in Conversations with Close Friends About Dating Relationships
}

\author{
Elizabeth M. Morgan \\ Boise State University \\ Neill Korobov \\ University of West Georgia
}

\begin{abstract}
The present study explores how close same-sex friendship groups participate in the coconstruction of identities in the interpersonal domain during young adulthood. Participants included 24 same-sex college student friendship triads (12 male and 12 female; 72 total participants) who took part in semi-structured group interviews that elicited stories about conversations with their friends about dating relationship problems. Qualitative thematic analysis revealed five common responses to dating problems evidencing identity work in the context of friends' conversations. These responses included relating the issue to one's own experiences, providing validation and encouragement, joking about the problem, offering advice, and providing concrete instrumental support. Results are interpreted with regard to gender differences and similarities as well as the social context of college and developmental context of emerging adulthood. The findings identify ways in which young adults are actively co-constructing and re-evaluating their interpersonal identities within conversations with close same-sex friends.
\end{abstract}

Keywords: close friends, romantic relationships, identity development

Erikson (1968) described committing to a cohesive identity as a central developmental task of adolescence. This task was allocated to adolescence because during the transition into and throughout adolescence, individuals increasingly engage in self-reflective behaviors, seeking to make meaning of themselves in relation to the social world. Following Erikson's specific considerations of identity surrounding occupational choice and ideology, Marcia (1966) conceptualized identity as domain specific, such that his semi-structured identity assessment interview specifically assessed occupational, religious, and political content areas. Later, Grotevant, Thorbecke, and Meyer (1982) were instrumental in advancing interpersonal relatedness as a significant domain of identity and further implicated its role in establishing "truly intimate relationships" (p. 39).

Despite being recognized as an important domain of identity, relatively little research has examined the social processes of adolescent and young adults' interpersonal identity formation. Given the developmental significance of both identity development and establishing intimate friendships and dating relationships during young adulthood (e.g., Arnett, 2004; Collins \& Madsen, 2006; Lefkowitz \& Gillen, 2006), gaining perspective on how experiences within friendships contribute to the development of young adults' interpersonal identity development is an important area of inquiry. The present study begins to explore these processes by examining how young adults co-construct their interpersonal identities in conversations with close same-sex friends about problems in or with dating relationships and dating partners, as well as concerns about the absence of a dating relationship.

\section{Interpersonal Identity Development}

Citing sex differences in identity development and the centrality of psychosocial processes in Erikson's theoretical perspectives on identity, Grotevant and colleagues (Grotevant et al., 1982; Thorbecke \& Grotevant, 1982) proposed that interpersonal aspects of identity should be considered in studies of identity formation. In particular, they suggested investigating the three areas of friendships, dating, and sex roles using Marcia's identity status interview. Later, recreation was also added to the interpersonal domain (Grotevant \& Adams, 1984). 
NOTICE: This is the author's version of a work accepted for publication by Elsevier. Changes resulting from the publishing process,

including peer review, editing, corrections, structural formatting and other quality control mechanisms, may not be reflected in this

document. Changes may have been made to this work since it was submitted for publication. The definitive version has been published in Journal of Adolescence, 2011. DOI: 10.1016/j.adolescence.2011.09.005

The relatively small body of research investigating interpersonal identity formation has identified differences based on several demographic factors. For example, research has consistently shown that women are more likely to engage in exploration in the friendship and dating domains than men (Bartoszuk \& Pittman, 2010; Cooper \& Grotevant, 1987; Lewis, 2003; Thornbecke \& Grotevant, 1982). Additionally, for both young adult men and women, identity achievement has been associated with the acknowledgment of both higher masculine and feminine characteristics, respectively (Bartle-Haring, 1997). The salience and exploration of interpersonal identity domain issues have also been found to increase with age throughout adolescence and young adulthood for both sexes (Allison \& Shultz, 2001; Bartoszuk \& Pittman, 2010).

Other studies of interpersonal identity formation have found it to be associated with various interpersonal tendencies. For example, identity achievement in the interpersonal domain has been associated with greater affiliation motivation (Hofer, Busch, Chasiotis, \& Kiessling, 2006) and the capacity for intimacy in young women when controlling for femininity (Bartle-Haring \& Strimple, 1996). Among young women, identity diffusion in the interpersonal domain has also been associated with emotion-focused coping strategies, while identity achievement was associated with greater use of problem-focused coping strategies (Mullis, Mullis, Schwartz, Pease, \& Michael, 2007). Young adults have also indicated higher exploration in the interpersonal than ideological domains (Bartoszuk \& Pittman, 2010) and it has been suggested that differential developmental pathways exist for these two domains (Bartle-Haring, 1997).

Despite the important information about interpersonal identity development gleaned from these previous studies, researchers have yet to identify the ways in which interpersonal relationships themselves promote or are involved in interpersonal identity formation. Furthermore, the majority of studies on interpersonal identity development have made use of quantitative methods of measuring participants' identity statuses or levels of exploration and commitment which may obscure some of the complexities and dynamics of these processes that are better captured through qualitative analysis. Given the salience of this domain of identity during young adulthood and the lack of research on the social contexts of its development, a more nuanced examination of the complex roles interpersonal relationships may play in young adults' interpersonal identity formation is needed.

\section{Identity Formation in Interpersonal Relationships}

Early theorists recognized that interpersonal relationships are especially significant social contexts for adolescent identity development (Erikson, 1968; Sullivan, 1953). For example, Erikson (1968) explained that adolescents learn who they are and how they fit into society by engaging in identity exploration in various social contexts. Sullivan (1953) also maintained that an individual's identity is realized through interpersonal relationships that validate selfworth. Current conceptualizations of identity development have extended these early perspectives, viewing identity development as a complex and dynamic process that is constructed and maintained by individuals in social contexts (e.g., Adams \& Marshall, 1996; Bamberg, 1997; Schachter, 2004; Thorne, 2004). The underlying idea of these perspectives is that as people co-construct their relationships with others, they are simultaneously engaging in the process of identity formation (Adams \& Marshall, 1996).

Identity control theory offers a useful approach for understanding how daily interactions between youth and significant others create dynamic identity processes that drive identity development (e.g., Kerpelman, Pittman, \& Lamke, 1997). This theory explains that identity is co-constructed through day-to-day interactions where adolescents and young adults are provided with identity relevant information in the form of social feedback. This feedback is then interpreted by the individual to create a self-perception of how others perceive them and their behavior. These interpersonal perceptions are then compared against the individual's current set of self-definitions, or identity beliefs. If the interpersonal feedback is congruent with one's identity beliefs, the identity is affirmed and strengthened. On the other hand, incongruent feedback has the potential to disrupt that identity belief, which can lead to enacting behaviors that help restore consistency between one's personal self-definition and social feedback. As a result, adolescents and young adults may seek to reaffirm their original self-perceptions through behavioral changes or by seeking out social situations that lead to new (and re-affirming) social feedback. Conversely, the individual may adjust their identity beliefs to correspond with the social feedback. This identity maintenance and change can promote both healthy and unhealthy growth. 
NOTICE: This is the author's version of a work accepted for publication by Elsevier. Changes resulting from the publishing process,

including peer review, editing, corrections, structural formatting and other quality control mechanisms, may not be reflected in this document. Changes may have been made to this work since it was submitted for publication. The definitive version has been published in Journal of Adolescence, 2011. DOI: 10.1016/j.adolescence.2011.09.005

This dynamic process of identity development is likely to occur in the context of meaningful and ongoing interpersonal relationships, which increases the likelihood that social feedback will be influential. Although research often focuses on parent-child relationships as important contexts of identity formation, close friends have been uniquely associated with relational identity development (Meeus, Oosterwegel, \& Vollebergh, 2002). Furthermore, in their study of possible selves, Kerpelman and Pittman (2001) found that peer feedback was specifically associated with identity exploration of highly important possible selves, suggesting that close relationships may be implicated in the co-construction of salient identity domains. Thus, close friendships are likely to provide dynamic social contexts for identity development in the interpersonal domain through interactions that convey social expectations and feedback.

\section{Close Friends and Romantic Relationship Development}

It has been argued that same-sex friendships are important contexts of identity construction and integral in developing later intimate and romantic relationships (Connolly \& Goldberg, 1999; Sullivan, 1953). Indeed, Paul and White (1990) maintained that in adolescence and young adulthood there is a conflation of identity development and intimacy development, with the two processes occurring simultaneously. In other words, young adults seem to discover who they are (identity) by exploring how they fall in and out of love (intimacy), making identity formation in this domain an interpersonal phenomenon (with friends). Furthermore, throughout adolescence and young adulthood, participation in dating and romantic relationships occurs gradually in the context of networks of samesex friendships (Brown, 1999; Feiring, 1999) and the majority of young adults simultaneously have close friendships and participate in romantic relationships (Collins \& Madsen, 2006).

Research identifying more general associations between friendships and romantic relationships helps substantiate the potential for close friends to also influence interpersonal identity development in the dating domain. For example, partner choices and the choice to date are subject to social influence by friends. Wood, Senn, Desmarais, Park and Verberg (2002) found that, compared to parents, media, and sex-education classes, late adolescents report that their friends have the most influence on their dating choices. Additionally, in a sample of college student couples, support from friends positively affected the quality of the couples' relationship and was associated with relationship longevity over time (Sprecher \& Felmlee, 1992). Korobov and Thorne (2007) also found that when given the prompt to have a "catch-up" conversation, close friends frequently discussed their dating and romantic relationship problems. Furthermore, discussions of sex-related topics are common amongst friends, particularly among young women and both young women and young men who are sexually active (Lefkowitz, Boone, \& Shearer, 2004). Consistent interactions with friends about sex, dating and potential dating partners provide numerous opportunities for young adults to receive identity-relevant information and feedback.

Studies have also identified that features of dating relationships show continuity with those of prior, same-sex friendships. In cross-sectional studies with adolescents, support derived from relationships with best friends uniquely contributed to the prediction of support in romantic relationships (Connolly, Furman, \& Konarski, 2000; Scharf \& Mayseless, 2001). Scharf and Mayseless (2001) also found that overall higher qualities of friendships were associated with higher capabilities for intimacy in romantic relationships. Recent research with young adults has also revealed associations between an achieved identity status and romantic relationship quality, but not friendship quality (Barry, Madsen, Nelson, Carroll and Badger, 2009). These results were interpreted as revealing a shift from the prominence of friendships toward romantic relationships during emerging adulthood. Overall, this research indicates that relationship patterns occurring within same-sex friendships may be transferred to romantic relationships and reveals the dynamic interconnections between these relationships during this period of development.

These studies offer many insights into the associations between young adults' close friendships and the ways in which these important relationships influence their dating experiences. However, they have generally failed to discuss the implications of these relationships for identity development, either in general or within the interpersonal identity domain. As a result, this body of literature substantiates the existence of close connections between friendships and dating relationships during adolescence and young adulthood, thus lending support for an investigation into the co-construction of interpersonal dating identity within these relationships as well. 
NOTICE: This is the author's version of a work accepted for publication by Elsevier. Changes resulting from the publishing process,

including peer review, editing, corrections, structural formatting and other quality control mechanisms, may not be reflected in this document. Changes may have been made to this work since it was submitted for publication. The definitive version has been published in Journal of Adolescence, 2011. DOI: 10.1016/j.adolescence.2011.09.005

\section{Present Study}

The goal of the current study was to provide a preliminary investigation into how young adults co-construct their interpersonal identities, specifically regarding dating, within relationships with close friends. To assess these processes of identity formation, a series of semi-structured interviews with three same-sex close friends were analyzed to identify conversational instances where friends discussed responding to or providing feedback about each other's dating experiences. This method was chosen because narrative approaches are especially useful for exposing complexities and dynamic processes of identity formation. Therefore, a qualitative methodology was particularly well-suited to explore the current study's research questions. Triads of close friends were chosen with the goal of producing more conversational, dynamic, and interactive data and because young adults typically have multiple close and mutual friends (Hartup \& Stevens, 1999).

The qualitative analysis of the present study specifically focused on the ways that young adults co-construct their interpersonal identities in conversations with close same-sex friends about problems related to dating and romantic relationships. It has been generally accepted that identity development is catalyzed by the negotiation of problems (Erikson, 1968; Sullivan, 1953), though this is often conceptualized as an internal process instead of one that occurs within interactions. However, the positioning and negotiations that occur when friends interact about relationship problems also likely catalyze identity development because the storyteller not only has the opportunity to offer a complaint, but the friend must offer social feedback. Following identity control theory (Kerpelman, Pittman, \& Lamke, 1997), the storyteller must then interpret the meaning of the friend's feedback with regard to her or his own identity beliefs. Furthermore, past research has found that it is more common for friends to discuss romantic relationship problems than non-problems (Korobov \& Thorne, 2007) and analyses of late adolescent self-defining memories have indicated that meaning-making was associated with problems more often than non-problems (McLean \& Thorne, 2003).

Due to the exploratory nature of this analysis, broad research questions and hypotheses were generated. First, because past research has suggested that same-sex friendship networks are entwined with romantic relationship development (e.g., Brown, 1999), it was anticipated that all friendship groups would report being involved with or appraised of each other's dating experiences and thus active in each other's interpersonal dating identity development. Next, based on identity control theory (e.g., Kerpelman et al., 1997), it was anticipated that friends would provide feedback on each other's dating experiences that would both confirm (and thus stabilize) and challenge (and thus alter) pre-existing self-perceptions. Lastly, because of consistent gender differences in studies of interpersonal identity formation (e.g., Lewis, 2003; Thornbecke \& Grotevant, 1982), it was anticipated that the young women's friendship groups would be more likely to provide evidence of identity work than the young men's groups.

\section{Method}

\section{Participants}

Participants included 24 triads of same-sex friends (12 male and 12 female). This yielded a total sample of 72 young-adult college students ( 36 men; 36 women) between the ages of 18 and 23 ( $M=20.0$ years, $S D=1.0$ years). Each triad was required to have known each other for at least six months and to have been "good friends" at the time of the study; interviews indicated that the majority of friends had known each other for one to two years, with several having known each other before college. Many of the friends indicated that they lived together in campus housing or in apartments. Self-reported quantitative closeness ratings with friends averaged $4.5(S D=0.7)$ on a scale from 1 (not at all close) to 5 (very close).

All participants were living away from home while enrolled in a public university in Northern California. The majority (64\%) of the sample self-identified as either 'Caucasian' or 'white' $(n=46)$; the remaining participants identified as 'Asian' $(n=10)$, 'Latino' $(n=6)$, 'Mixed' $(n=8)$, or declined to state their ethnicity $(n=2)$. Almost all participants identified as 'heterosexual' $(n=66)$ with four women identifying as 'bisexual' and one man identifying as 'unsure'. Just under half (46\%) of the participants were in a romantic relationship with either a local or longdistance partner at the time of the study $(n=33)$. 
NOTICE: This is the author's version of a work accepted for publication by Elsevier. Changes resulting from the publishing process,

including peer review, editing, corrections, structural formatting and other quality control mechanisms, may not be reflected in this document. Changes may have been made to this work since it was submitted for publication. The definitive version has been published in Journal of Adolescence, 2011. DOI: 10.1016/j.adolescence.2011.09.005

\section{Procedures}

Participants were recruited for the study through informal requests for volunteers in both upper and lower-level social science university courses. The study was described as a research project looking at how young adult samesex friends talk about their dating experiences. They were informed that participation involved attending a lab session in groups comprised of three same-sex friends and were informed that they would be compensated with $\$ 15$ each (\$45 per friendship group) for their participation. Upon indicating interest in the study, a potential participant received an email with information about selection requirements for their two friends (a "good friend" who they had known for at least six months). This individual then selected two friends and provided their contact information. Appointments were arranged with participants until 12 male and 12 female triads were interviewed. Interviews took place in a research room on campus. After providing informed consent, including a review of confidentiality, the group interviews were audiotaped. Group interviews lasted on average 1.5 hours. Each group member then individually completed an associated paper and pencil questionnaire, which took approximately 30 minutes. The study was approved by the Institutional Review Board at the university where the research took place.

\section{Measures}

The group interviews were semi-structured and included a series of six prompts formulated to elicit small stories about everyday events (see Ochs \& Capps, 2001; Bamberg, 2004). Questions inquired about memorable experiences with dating partners, problems with dating partners, the importance of having a dating partner, and conversations between the friends about these and other relationship issues. Participants were also asked to discuss what they each thought of their friends' current and past dating partners. Relationships discussed usually included those that took place directly before or during college. A male researcher moderated the discussions with the young men and a female researcher moderated the discussions with the young women. Both moderators attempted to create a space where the participants felt free to engage in the kinds of conversations that occurred naturally in their everyday contexts. As a result, the discussions were fluid and follow-up questions were necessarily unscripted.

\section{Analysis}

The preliminary analysis included a team of four research assistants reviewing the transcripts to identify each instance in which a problem regarding one or more friends' dating or romantic relationship circumstance was discussed. This process involved all research assistants reviewing and meeting to discuss identified "problems" within two transcripts per week. As such, the process of defining and identifying problems was iterative and collaborative with multiple and ongoing reliability checks. When disagreements about the presence of a problem occurred, they were resolved within meetings with the research team. After all transcripts were reviewed and discussed by the research team and a list of problems was generated for each transcript, the research team again reviewed all of the transcripts to ensure that all problems were appropriately acknowledged; 162 problems were ultimately identified (81 each in the female and male groups). Although not systematically classified, these problems included issues that occurred within established romantic relationships (such as uneven reciprocity or the dissolution of the relationship), issues that occurred because the person was not in a relationship (such as being lonely, attempting to initiate relationships, or solidifying a relationships status with a new partner), and problems that spanned multiple relationships (such as seeking disengaged, unavailable, immature, or emotionally damaging partners or personal difficulties with commitment).

Following the identification of a problem, the transcripts were then reviewed to identify the specific ways the other two friends reported having responded to the issue; 184 responses were identified (116 from female groups, 68 from male groups). Using a thematic analysis approach (Braun \& Clarke, 2006), patterns within friends' responses to the problems were grouped into emergent themes, which were developed within discussions between the first author and a research assistant. These emergent themes were then refined through discussions and reviews of the data to provide inclusive and meaningful categories. The first author and a research assistant then both systematically classified all of the responses into the finalized categories. Adequate interrater reliability was obtained (Kappa $=.88$; 92\% agreement). Disagreements were resolved in conversations between the two coders. Five male responses and three female responses were not included in any of the categories due to lack of detail or relevance. 
NOTICE: This is the author's version of a work accepted for publication by Elsevier. Changes resulting from the publishing process,

including peer review, editing, corrections, structural formatting and other quality control mechanisms, may not be reflected in this document. Changes may have been made to this work since it was submitted for publication. The definitive version has been published in Journal of Adolescence, 2011. DOI: 10.1016/j.adolescence.2011.09.005

\begin{abstract}
Results
The five most commonly described exchanges with regard to interpersonal identity-related issues within the samesex friendship triads included: relating the issue to one's own or others' experiences, providing validation and encouragement, joking about the problem, offering advice, and providing concrete instrumental support. Each of these themes, and the ways in which these responses evidenced identity work, are described below with representative quotes. Selected excerpts from the conversations are representative of the theme and participants' names have been changed.
\end{abstract}

\title{
Relating the Issue to Past Experiences
}

Both male and female friends frequently described comparing and relating their friends' dating problems to the same or a similar problem they were familiar with or had experienced themselves. Although friends would typically be relating a personal past experience, occasionally friends would be concurrently experiencing similar issues and jointly work through the issue, making sense of it as they experienced it together. Nine of the female (21 responses total) and nine of the male triads (13 responses total) described this identity-reaffirming approach at least once. Examples of shared issues within female groups included getting into or staying in bad relationships out of fear of loneliness, feeling guilty or confused after having casual sexual encounters, handling break-ups, and juggling boyfriends and family. Examples of shared issues within the male groups included having difficulties finding dating partners, feeling insecure at the beginning of a relationship, having unequal feelings in a relationship, and handling upset girlfriends. For example, in the following exchange with a male triad, Hank described that he was looking for a girlfriend when Gary (who was currently in a relationship) explained that he felt the same way several months ago.

Hank: I actually try to get into a relationship this year, like a serious relationship that I care about, and, like, pretty much all I've been doing for the year and a quarter is just hangin' out with the guys, so...

Mod: So why is it that you want to do this new thing?

Hank: I don’t know, I don’t know really, but...

Gary: I can see what he was going to say cause I kinda got something going on, but before, like, early September, I remember I was thinking it would be great to track down a girlfriend. (Moderator: yeah) Yeah it'd be nice.

Moderator: You thought that-

Hank: It would be nice.

Moderator: You wanted to track down a girlfriend?

Gary: Track one down, yeah.

Hank: Like a safari.

Gary: Like a safari, nah.

Moderator: So you can relate to what he said?

Gary: Yeah, yeah definitely.

In this excerpt, Hank begins by explaining his desire to be in a serious relationship and, offering up a response within the interview itself, Gary validates Hank's "new" interest in finding a girlfriend because he remembers feeling the same way earlier in the year. Following identity control theory, the interpersonal feedback provided by Gary that offers acceptance and helps normalize Hank's interest in finding a steady dating partner would result in a non-disruptive comparison between Hank's identity standard and self-perception, thus potentially re-affirming Hank's desired exploration of a novel aspect of his interpersonal dating identity. 
NOTICE: This is the author's version of a work accepted for publication by Elsevier. Changes resulting from the publishing process, including peer review, editing, corrections, structural formatting and other quality control mechanisms, may not be reflected in this document. Changes may have been made to this work since it was submitted for publication. The definitive version has been published in Journal of Adolescence, 2011. DOI: 10.1016/j.adolescence.2011.09.005

Another example from a male triad revealed the ways in which two friends could connect with each other's problematic relationship dynamics to reaffirm the struggles they were experiencing as customary issues in young adult romantic relationships. In this story, Dave had explained that he broke up with his girlfriend because of his constant need to "babysit" her and Aaron relates Dave’s experience to his own recently terminated relationship.

Dave: Yeah she needs it, like she's, she gets ridiculous when she drinks, she, like, just consistently blacks out, does something horrible to herself on accident.

Brandon: Yeah.

Dave: "What did I do last night guys?” And it's like she had, like playing drinking games was gonna wax a guy's legs a few weeks ago, or a few months ago, and she heated up some Nair in the microwave, and she pulled it out, she was just "Blah" and spilled it all over herself, like boiling hot, and she has these huge scars now, (Aaron: Third degree burns) and she had like all the skin bubbled and boiled off. And then she like didn't know how to take care of it either, like she popped the blisters and it's just like "No!" Like, you make a blister as a protection for your skin, and so we'd like bandage her hand up and clean it for her and stuff, and (Moderator: Yeah) so she's like "Man I really shouldn't be drinking so much anymore” but then like the next night (drinking sound effect) and, like, when she starts drinking, it's just, I can't, like, understand it. But, maybe, I don't know, she's Russian, maybe it's just in her genetics to be alcoholic.

Brandon: Pretty common stereotype.

Moderator: Wow.

Aaron: But it kinda seemed like, with the same thing that happened with me and Hannah, you had to like, kind of keep her out of a rut, like try your hardest, like that's how I feel a lot of the time, like, constantly, like, lifting Hannah out of this like well, you know?

Brandon: It’s so energy consuming.

Aaron: And yeah, it takes, like, all my energy just to, like, pull this rope, you know? And then, like, I get her up and then, boom, down the next day, you know. Every day, it would just be like pulling her out of this hole. And I kinda saw that with you guys.

In this exchange, Aaron substantiates Dave's frustration and choice to break off the relationship by offering up his own relationship experience. Furthermore, despite not offering his own experience, Brandon also corroborates both Dave and Aaron's positions. As a result, the group has established that dating relationships where there is a continual need to take care of a partner are not desirable. Regarding interpersonal identity formation, these types of exchanges, where identity congruent feedback is being offered within close friendships, likely function to reaffirm and stabilize all three young adults’ identity standards about their roles vis-à-vis taxing dating relationships.

A third example of this type of exchange took place within the interview itself as two female friends heard about Lily's recent casual sexual encounter with Grant for the first time. Lily regrets the experience and Nellie downplays the negativity of the situation, reminding Lily that she had a similar experience the year before.

Lily: Oh, and then hot guy, Grant.

Jessica: Oh, we don't know him.

Lily: Dude, you guys. I probably didn’t tell you guys about him.

Jessica: Oh that's alright. ((laughter))

Lily: I didn’t tell...did I really not tell you? 
NOTICE: This is the author's version of a work accepted for publication by Elsevier. Changes resulting from the publishing process,

including peer review, editing, corrections, structural formatting and other quality control mechanisms, may not be reflected in this document. Changes may have been made to this work since it was submitted for publication. The definitive version has been published in Journal of Adolescence, 2011. DOI: 10.1016/j.adolescence.2011.09.005

Nellie: No.

Lily: Oh, this was, yeah, recent. That's...it was like...it's was right bef-...you had already gotten to Canada and you had already got home. It was right before spring break (Nellie: spring break). But I probably didn’t tell you because I wanted to erase it from my head 'cause it was stupid. Like, I'm not even (Nellie: ((laughs))) like this at all. But he...it seriously like...honestly, I think one of the...or like the hottest just to look at (Nellie: ((laughs))). Hottest guy I’ve ever seen, ever. Like really, like ever I think. But he's like stupid and ((laughter)) and like...just like a dirty guy, I'm sure. 'Cause he was hot and then... ((laughter)) But yeah, anyway, he is really, really, really, really good looking, but that means nothing.

Nellie and Jessica: ((laugh))

Lily: and uh...but yeah no...he just came over that night (Nellie: ((laughs))) and um... but we didn't like...I don't know, whatever (Nellie: ((laughs)). We did too much I think, 'cause I'm like, I don't know. I’ve been getting into ((laughter)) I don’t know. But um...no, we didn’t like, whatever...

Nellie: ...do much.

Lily: For most people I don't think that it's much, but I think is too much for me... and like I'd never. And like I always see him at school now and I don't want to see him 'cause I'm like “ugh.”

Nellie: And that's the deal.

Lily: I thought you knew about him.

Moderator: So you weren’t interested in anything more? Like you weren’t interested in seeing him anymore?

Lily: No, and I wish I could...I wouldn’t...I would seriously take it back and just not had...have him come over.

Nellie: I don’t think it’s bad. I had that last year (Jessica: Yeah) with just like someone who's like...I knew I could never date, but I didn’t want to date anyone ‘cause I had just gotten over a long (Lily: long) relationship.

During this new exchange of information taking place within the interview, Lily explained that she did not tell her friends about this experience because it was "stupid" and that she is "not like even like this at all." She continually reiterated that although he was attractive, he was "dirty" and that they "did too much.” To help Lily make sense of a sexual encounter that was obviously incongruent with her current interpersonal identity standards, Nellie offered herself as an example that it is occasionally okay to engage in that kind of behavior. In this exchange, Nellie's reminder to Lily about her past behavior offers Lily a model for how one's sexual repertoire can simultaneously include casual and more serious sexual experiences, and thus could serve to lessen the tension created by Lily's engagement in a behavior that is not consistent with her current identity beliefs. As a result, this exchange would provide Lily with social feedback that could enable her to safely explore alternative identity possibilities and even potentially integrate this experience into her interpersonal identity.

\section{Validation and Encouragement}

In addition to relating a friend's experiences to one's own to normalize the experience, participants also engaged in exchanges that offered validation and encouragement for each other's interpersonal struggles. This type of exchange was described at least once in all 12 of the female triads (36 responses total) and in eight of the male triads (14 responses total). The motivations behind these discussions were focused on encouraging the individual to pursue a course of action based on their previously expressed concerns and desires. They typically involved providing acknowledgment and acceptance for the individual's experiences and interpretation of the issues at hand, including makings comments that were emotionally encouraging, elaborating on elements of the problem, and siding with the friend. As a result, these conversations would not necessarily alter the friend's self-perceptions; rather, these 
NOTICE: This is the author's version of a work accepted for publication by Elsevier. Changes resulting from the publishing process,

including peer review, editing, corrections, structural formatting and other quality control mechanisms, may not be reflected in this document. Changes may have been made to this work since it was submitted for publication. The definitive version has been published in Journal of Adolescence, 2011. DOI: 10.1016/j.adolescence.2011.09.005

responses would push the individual toward behavior that was congruent with their established identities. The background to the following example was that Julie recently broke up with a boyfriend who everyone (including Julie) agreed was not treating her well.

Carrie: We'd have a lot of like late night talks about it and um, I just, it just really really got to me, like I mean I was telling her throughout this whole thing, "If he has time to piss, he has time to call you." ((group giggle)) Like, and like, she was like "yeah" and then there was this one incident where like, it was Friday and she was gonna go over to his house and she called him to ask him to come pick her up, um and he was like, "Um, I'm just gonna send Tom (who was his roommate) because I'm in the middle of a raid right now." (Julie: Yeah) I think that was the term, and like, she was just laughing like "that's so cute," and I'm like, "Julie, he's not even taking 10 minutes to come pick you up” like...

Julie: My way of coping trying to hide what I was actually feeling.

Carrie: Yeah, and like, I just, yeah, I was telling her like throughout this whole thing, you know, you don't, like, deserve to be in a relationship where, like, he can't even like spend, like, and, and yeah, he was pretty busy during the week I think, but on Fridays, he was not busy and he like did not take like two seconds to just come pick her up or just come to hang at the apartment like, (Julie: Yeah) I mean, she, and she went to like, she went, cause they were having some competition game thingy at the Fireside lounge (Julie: And I went!) and, like, she went and like everybody else, (Julie: To support my boyfriend!) she was like the only girlfriend there I think, and like. . . ((group laughter))

Julie: And he even wanted me to stay there when I just wanted to show up for five minutes, he's like "Oh stay!”

Carrie: Yeah, so. Yeah. I'm, I’m glad you got out of that, even though it still hurts I think (Julie: Yeah) but I'm still glad you got out of that relationship.

This dialog narrates Carrie's previous and ongoing efforts to help Julie see that her boyfriend's behavior was not part of a desirable repertoire, which Julie readily admits, but was obviously willing to put up with for the length of time she continued dating him. Carrie also recognized that Julie was emotionally invested in the relationship and that she was hurt when it ended, but assertively explained why his behavior was not acceptable, thus encouraging Julie toward adopting higher standards for dating partners. The relevance to interpersonal formation in this exchange comes in the form of feedback from Carrie that was incongruent to Julie's interpersonal identity standard (which somehow valued staying in a relationship where her dating partner was not reciprocally engaged). Given that Julie did eventually end the relationship, identity control theory would suggest that Julie's comparison between her own identity standard with an incongruent self-perception based on this ongoing social feedback disrupted her identity in such a way that she was forced to re-evaluate and even modify her identity standards. Carrie's continued affirmation that she was "glad you got out of that" could serve to strengthen Julie’s new or adjusted identity beliefs.

In the next example, Paul's friend Brady not only provided an empathetic ear, but also stepped up to take an active role in helping Paul avoid masturbating, which he believed he struggled with in the past as well as during his current dating relationship. First, Paul explained how much of a problem this was in his life.

Paul: Like a few weeks ago, or like a month ago, um, like, before I started going out with Pennie and, like, three months into our relationship I had gone, like, a year without masturbation and, like, it was, like, a huge, like, area where I felt like I experienced a lot of healing from God after like years of struggling with it and not being able to tackle it or whatever you want to say, like, (Moderator: right) like, finally getting that, like, kind of rest from it and like it allowed me to like really focus on my like my relationship with God without that added frustration of always feeling, like, I'm failing right (Moderator: right, totally) and so that was, it was such an awesome time but, you know, I'm weak, I'm a guy, like I failed again and so I don't know that was pretty demoralizing and then pretty much from that point on I just, like, couldn't shake it again or whatever and like just trying to get help and like talking to people about it and through this time, like, continuing to grow in my relationship with Pennie and so I kind of felt like I was living a double life because I had tried to keep her away from it and I tried to keep it away from her as far as, like, my problem with lust. 
NOTICE: This is the author's version of a work accepted for publication by Elsevier. Changes resulting from the publishing process,

including peer review, editing, corrections, structural formatting and other quality control mechanisms, may not be reflected in this document. Changes may have been made to this work since it was submitted for publication. The definitive version has been published in Journal of Adolescence, 2011. DOI: 10.1016/j.adolescence.2011.09.005

After further explaining the issue, Brady explains how he would help discourage Paul from masturbating so frequently.

Brady: Yeah, Paul and I used to be accountability partners and it would be a deal where like if one of us failed, like, the other would hit them (laughter) and so it was like, 'think about me getting you in the arm (Moderator: wow) if you think about that' you know.

Paul: We never actually hit each other.

Brady: I hit you once.

Paul: Oh did you?

Brady: Yeah.

Acting as an "accountability partner," Paul and Brady were able to encourage each other toward behaviors congruent with their values and ideal selves. Receiving supportive social feedback from Brady allowed Paul to maintain his established identity standards for his own sexual behaviors, despite perhaps having received information from other social outlets that were not congruent with his belief system. Later, Paul explained how he was able to talk about the issue with Pennie and described how valuable that experience was. His ability to both manage his masturbation and have productive conversations about it in his dating relationship was likely scaffolded by his conversations with his friends and the validation he received from them.

\section{Joking about the Problem}

Not all conversations between friends simply supported previously existing interpersonal identity beliefs. One of the ways that friends exerted slight pressure to alter each other's behaviors was by joking about the problem. This type of response most often occurred through teasing the individuals involved or more generally making jokes about the problem or situation. Six of the female triads (8 responses total) and four of the male triads ( 7 responses total) described joking about friends' relationship issues. In both male and female triads, joking usually surrounded "hook up" situations where there was something unique about the situation, such as one young man getting a call from a person he had sex with who might have herpes and a young woman who was briefly involved with a professional baseball player when she worked for the team (which was not allowed). In these instances, joking typically was used because the behavior was viewed as unconventional or deviant by all parties involved and held entertainment value. Other joking occurred in response to more general patterns of behavior, such as being single or, as with the following example, having too many casual sexual encounters.

Gary: The other morning we were walking back from the dining hall and he said "you know I've been doin' some thinkin'” and I said "oh yeah Hank what've you been thinking about?” he's like "I think I'm going to stop being so easy.” ((laughter)) I was like “yeah? Why?” He’s like, well, "I’ve never turned down sex in my life, I don't care who it is, I just can't.” And he’s just like "huh” and like "maybe you should go to a meeting or something.” ((laughter))

Hank: I believe he urged me not to stop, because it’s funny. ((laughter))

Gary: Maybe.

Moderator: So you actually, what's your version, the story of that walk back? Did you actually bring it up just like that?

Hank: Yeah pretty much, I believe I said, used the phrase "stop being so easy to bed" but other than that and he laughed and said "now why would you want to do that" and I said "yeah," it just kind of seemed, oh I brought it up cause it kind of seemed like something that I should try to work on.

Moderator: You're serious. 
NOTICE: This is the author's version of a work accepted for publication by Elsevier. Changes resulting from the publishing process,

including peer review, editing, corrections, structural formatting and other quality control mechanisms, may not be reflected in this document. Changes may have been made to this work since it was submitted for publication. The definitive version has been published in Journal of Adolescence, 2011. DOI: 10.1016/j.adolescence.2011.09.005

Hank: Well, ((laughter)) it’s a good concept to go towards.

Moderator: So it’s an aspiration of sorts.

Hank: Yeah, kind of an aspiration.

Moderator: But Gary seemed to - what was your take on why he laughed or what his response was? What was that message he was sending?

Hank: Because my promiscuity produces funny stories. ((laughter))

Gary: Yeah, that's actually, exactly a good way put to it, that's exactly it. ((laughter))

Hank: Which I enjoy as much as he does.

Gary: It's just the entertainment value of it I guess.

Moderator: Is that important among guys to have that?

Gary: Yeah, I’d say so.

Hank: I don’t know. It’s important among me ((laughter)) and my friends.

Moderator: To be able to provide that kind of entertainment for your friends?

Hank: Yeah, to have funny stories to tell.

Gary: I think everyone likes to have funny stories I think, yeah. So why not get out there and make some?

Joking about patterns of behavior was typically used to suggest alternative patterns of behavior to friends in a lighthearted manner, with variable success. In this narration, Gary had encouraged Hank to continue his current behavior for the benefit of the group, and, as a result, was not supporting Hank's interest in being more responsible because it would result in fewer entertaining stories. Regarding the application of this exchange to identity control theory, Gary was providing Hank with identity incongruent feedback, such that Hank had decided to explore and potentially establish a different set of interpersonal identity beliefs, but received feedback from Gary that this identity adjustment was not socially desirable. However, because the conversation was generally conducted in a humorous manner, it is difficult to assess the meaning that either Hank or Gary took away from it. It is also important to note that this is the same pair of friends who previously discussed interest in finding dating partners, thus suggesting that despite the possibility of fewer funny stories about Hank's sexual escapades, Gary is supportive of Hank's interest in trying to establish a serious relationship.

Not all joking occurred in response to unusual or inherently funny situations. For example, one pair of friends described how they joked about being the "children of divorce" when their third friend broke up with her long-term boyfriend. Another female triad described their pattern of joking about the one friend who did not have a dating partner being the "fifth wheel" in their group. Here, humor provided a safe space to express ideas about the significance of establishing and maintaining dating relationships, especially for the benefit of the friendship group. Due to the ambiguity of this form of social feedback, it is possible that the implications for identity adjustment (i.e. changing one's identity standards based on this feedback), would be mitigated.

\section{Offering Advice}

Often mixed in with validation and encouragement was advice. Here, friends weighed in with their views of the situation and generally proposed a course of action for the individual. What was unique to this category was that the friend's advice typically augmented the current perspective or position expressed by the individual and was not necessarily congruent with the individual's expressed desires. Ten of the female triads (33 responses total) and eight 
NOTICE: This is the author's version of a work accepted for publication by Elsevier. Changes resulting from the publishing process, including peer review, editing, corrections, structural formatting and other quality control mechanisms, may not be reflected in this document. Changes may have been made to this work since it was submitted for publication. The definitive version has been published in Journal of Adolescence, 2011. DOI: 10.1016/j.adolescence.2011.09.005

of the male triads (27 responses total) described this approach at least once. Examples of advice offered included how to interpret a dating partner's (or potential dating partner's) behaviors, appropriate ways respond to a dating partner, and how to find dating partners. The following example is typical of friends offering advice, such that Melanie validated and asserted Meg's negative appraisal of her past relationship and offered her advice about how to proceed once she terminated the relationship. Toward the end, Jennifer also weighed in on why Meg may be engaging in a harmful pattern.

Meg: So, I came to school with a boyfriend, and that was one of the worst relationships I think I could...I ever had. I could say, yeah.

Jennifer: Yeah.

Meg: That was all about just being in a relationship and I was straightforward about that with them, but that's what it was about. And I know it sounds awful but... and, uh, it ended on my birthday. I went home and I hadn't seen him for seven weeks and we saw each other that night and then like into the morning, so it was my birthday. And then he left and he sent me an email at like 2:30 in the morning through MySpace, breaking up with me on my birthday. And...I called Melanie and I was bawling. Yeah like...

Melanie: Completely, yeah.

Jennifer: Yeah.

Meg: It...it wasn't about him...I think it was more like...

Melanie: He is horrible. Just horrible for somebody to do that to you on your birthday. I mean, she's still like emotional about it. Like, that's just horrible. Even if, like, you didn't know if you truly liked the guy, it's just that's such a horrible thing for somebody to do. Like, that's such, I mean that's horrible for somebody to do so...you know, that's why it was like, "well, you know, you need to before you can, you know, ask for somebody to love you need to love yourself' so that's why you're on the "no dating," you know.

Melanie: So...so it’s like "you need concentrate on yourself and....and, you know, put yourself”((something unintelligible))

Moderator: Did you guys sit down, did they sit down and talk with you?

Jennifer: We actually did, yeah.

Moderator: So you guys had to do a little...little intervention?

Jennifer: Yeah.

Melanie: Well sort of.

Jennifer: Well, 'cause we've seen...um...we've know her for like a year or so, so like we've seen other people she likes and its often like....and the same thing goes for me, the people who give you the attention always aren’t the people who care about you...

Melanie: Mmhmm

Jennifer: ....and like sometimes those are the ones you're the most receptive to because it's always nice to feel like someone likes you or someone's like paying attention to you and

Meg: I...I

Jennifer: Like, she just - 
NOTICE: This is the author's version of a work accepted for publication by Elsevier. Changes resulting from the publishing process, including peer review, editing, corrections, structural formatting and other quality control mechanisms, may not be reflected in this document. Changes may have been made to this work since it was submitted for publication. The definitive version has been published in Journal of Adolescence, 2011. DOI: 10.1016/j.adolescence.2011.09.005

Meg: I have pattern

The narration of this previous interaction between Jennifer, Melanie and Meg evidences complete support for Meg's emotional well-being, including vehemently asserting how "horrible" her ex-boyfriend was. They then used that experience to push Meg toward greater introspection about her relationship patterns. As a result, Meg and her friends have co-constructed an interpersonal identity for Meg that involves a "pattern" of behaviors leading her toward unhealthy relationships. It appears as if Meg has accepted this identity and incorporated it into her identity standard, which was potentially developed and likely strengthened by her friends' feedback.

In the next example, Sam was new to the dating scene; he explained that he was "trying to learn and at the same time trying to get into it.” His friends reported that he asked everybody for help and advice, including when to call his new girlfriend and what to do for her for Valentine’s Day.

Sam: The best advice was like, do whatever you feel like is like good for her, you know.

Moderator: All right.

Rick: I said that.

Adam: Who told you that?

Sam: Yeah, Rick told me.

Moderator: Do whatever you feel like is good for her?

Sam: Yeah.

Moderator: So in other words, like, figure out what her needs are what she likes and try to like, make her feel good.

Sam: Yeah.

Rick: Yeah, I just feel like he shouldn’t use everyone else’s approach, you know.

Adam: You gotta be yourself.

Rick: I feel he should do what he feels comfortable doing.

In this narration of a previous interaction, Sam was actively engaging his friends in his interpersonal identity development because of his lack of knowledge about how to behave in dating relationships. In this case, he appeared willing to engage in identity exploration processes by eliciting feedback and information from his friends that could serve to establish what may have originally be a fairly diffuse interpersonal identity. Their advice appeared to include both a message to "be yourself" and to not try to take on a false identity in the relationship as well as to be sensitive to your partner's needs. Because Sam reiterated the second part (to do whatever you feel is good for her), Adam and Rick made sure that the "be yourself" message was also reviewed, perhaps because they wanted to make sure that both perspectives were reflected in the account of this exchange.

\section{Providing Instrumental Support}

Less common, but similar to offering advice, participants described facilitating activities and providing tools for their friends to help them make decisions about how to resolve or respond to a relationship problem. This typically took place if the friend was unsure about what to do and was generally described as a highly collaborative effort. Seven of the female triads ( 15 responses total) and two of the male triads (2 responses total) described this approach at least once. Typically, the friends engaged in a directed problem-solving activity, such as in the following example where Diana and Jane were assessing if a break-up after a prolonged period of turmoil in a long-term relationship was the best course of action for Diana and her boyfriend. 
NOTICE: This is the author's version of a work accepted for publication by Elsevier. Changes resulting from the publishing process,

including peer review, editing, corrections, structural formatting and other quality control mechanisms, may not be reflected in this document. Changes may have been made to this work since it was submitted for publication. The definitive version has been published in Journal of Adolescence, 2011. DOI: 10.1016/j.adolescence.2011.09.005

Diana: Remember me and you made that checklist after we broke up?

Jane: Oh yeah ((laughing)) that’s right.

Diana: Like me and her made this list of like good and bad things about our relationship. We were, like, on campus and I was just like really, like, "I don't know what I'm doing” 'cause we were already hooking back up. And I was like, “I don’t know if I want this” and we, like, ended up making (Jane: yeah) like a list of like very specific things and she helped me. She was like "well he, you know, if he did this..."

Jane: We had like a system of stars like...

Diana: Yeah, like, how much important is that compared to this?

Jane: How important is this? Five stars... ((laughing)

Diana: So I'd have like, or like, we had like three happy faces sometimes like two for something.

Jane: ((laughing)) Frowning faces. ((laughter))

Diana: It was stupid but, like, it helped me.

Moderator: Was it helpful?

Diana: Yeah, I think it ended up like there was more bad things than good and like you were really just like "no, you shouldn't get back together with him."

Although it seemed as though the checklist was Jane's idea, Diana was highly engaged in the process and did find it useful. The act of collaboratively classifying a dating partner's behaviors as more or less positive evidences the ways in which these young adults' interpersonal dating identities are co-constructed within close friendships. In this example and others within this category, emphasis was placed on the cooperative effort of both parties to engage in activities that would enable the individual to come to a conclusion independently of the friend's opinion. The interactive process would offer the individual interpersonal feedback that could disrupt or affirm a pre-existing identity belief, and thus contribute to identity stability or change.

In a similar technique with a different issue, Kelsey’s friends tried to help her feel better about not having a dating partner on her $21^{\text {st }}$ birthday.

Kelsey: They made a list of guys ((mutual laughter)) that I could possibly like. ((mutual laughter))

Laurie: 'Cause like she was talking about what she wanted to...about...okay 'cause her birthday was coming up on Tuesday and this was Monday and so we were - she was like talking about how much she wanted to, like, be with someone and she was just so frustrated ((Jackie laughing)) and [muttered couple words] and Annie was there too, and so we were just like -

Kelsey: and Michael

Laurie: - I was like, oh yeah, but they were like, that's it. Okay, we are gonna make a list of all the people that maybe you can, like, mess around with or kiss. You don't have to do anything. ((Jackie laughing)) You just, like, even you could just like ((Jackie laughing)) kiss them or like maybe cuddle with them or like ((mutual laughter)) anything and so we made a list of twenty-one 'cause it was her twenty-first birthday ((mutual laughter)) so we made a list of twenty-one people, twenty-one guys and girls [Jackie: yeah] and, um we were just like all laughing about it. ((laughing))

Jackie: Yeah it was just a funny thing. 
NOTICE: This is the author's version of a work accepted for publication by Elsevier. Changes resulting from the publishing process,

including peer review, editing, corrections, structural formatting and other quality control mechanisms, may not be reflected in this

document. Changes may have been made to this work since it was submitted for publication. The definitive version has been published in Journal of Adolescence, 2011. DOI: 10.1016/j.adolescence.2011.09.005

This somewhat lighthearted approach to helping a friend find potential dating (or "cuddle") partners actually contains a number of implications for young adults' interpersonal identity development. Not only were the friends' validating Kelsey's concern about not having a partner, but also furthering the notion that brief sexual encounters with friends or acquaintances (both male and female) are appropriate short-term ways to satisfy a desire for a relationship. Furthermore, the celebratory aspect of this list (connected with her $21^{\text {st }}$ birthday), promoted a playful, but not romantic, perspective of these activities. If Kelsey’s identity standards were not previously congruent with this feedback, these exchanges could serve to disrupt her identity and challenge her to either reconcile her behavior with the feedback (by kissing multiple people at the party), or seek further feedback that is more consistent with her existing identity standard.

\section{Discussion}

The primary goal of this study was to examine the ways in which friends are involved in the co-construction of interpersonal identities through their conversations about dating and romantic relationships. Preliminarily, it was determined that each friendship group was involved with or appraised of each other's dating experiences and narrated multiple instances of social feedback about each other's behaviors, with giving advice and providing validation and encouragement as the most common forms of feedback. This finding is not surprising given the developmental significance of both establishing close friendships and dating relationships during emerging adulthood (e.g., Arnett, 2004; Collins \& Madsen 2006) as well as the salience of interpersonal identity issues during this development period (Bartoszuk \& Pittman, 2010). Furthermore, research has established that discussions of dating and sex-related topics among same-sex friends in college are common (e.g., Lefkowitz et al., 2004) and that peer attachment is associated with relational identity development (Meeus et al., 2002). Following the recognition that these types of interactions indicate active processes of identity formation (Adams \& Marshall, 1996), the ubiquity of these exchanges indicates that close friends are indeed highly participatory in the formation of interpersonal dating identities within this population.

In addition to providing general evidence that identity work was occurring within these interpersonal relationships, the emergent themes of friends' responses to relationship issues indicated that friends were both supporting and challenging each other's self-perceptions. The ways in which friends corroborated each other's experiences in the dating arena occurred most frequently when friends related the issue to their own or others' experiences and provided validation and encouragement, which was one of the most common responses. In these exchanges, friends offered support for each other's choices about issues such as starting and ending relationships, their interpretations of dating or sexual partners' behaviors, and sexual behaviors. The corroborating feedback and information friends provided to each other as they negotiated these developmentally appropriate dating problems were typically wellreceived and likely served to maintain and strengthen interpersonal identity beliefs. It is important to recognize that not all interpersonal identity beliefs that were being reinforced were necessarily "healthy" for the young adult, such that not all personal, partner, or relationship assessments that were verified by friends were necessarily accurate or adaptive.

Friends also gently, or more forcefully, challenged each other's self-perceptions when joking about the problem, offering advice, and providing concrete instrumental support. In many of these types of exchanges, participants described supporting a friend by pushing them to consider alternative perspectives or pursue a course of action with regard to their dating issue that was not directly aligned with the individual's own preferences. Following identity control theory, the presentation of social feedback that diverged from the individual's self-perceptions is likely to facilitate identity exploration (Kerpelman \& Lamke, 1997). Furthermore, instrumental support that challenged individuals' self-perceptions may have particularly enabled exploration given that past research has found problemfocused coping to be associated with identity achievement (Mullis et al., 2007).

Quantitative comparisons of interpersonal identity formation in young men and women have frequently revealed that young women engage in higher levels of exploration and are more likely to be classified as identity achieved in this domain than men (e.g., Lewis, 2003; Thornbecke \& Grotevant, 1982). Despite not providing an assessment of interpersonal identity formation directly, the present study revealed that young women describe a much higher number of responses per problem (1.43 responses per problem for women and 0.84 responses per problem for men), providing evidence that active interpersonal dating identity work occurs more frequently, or at least was recounted more often, among close female friends than close male friends. Nonetheless, these results should be interpreted with caution given that the sample was small and these differences may be attributed to idiosyncratic individual or 
NOTICE: This is the author's version of a work accepted for publication by Elsevier. Changes resulting from the publishing process,

including peer review, editing, corrections, structural formatting and other quality control mechanisms, may not be reflected in this

document. Changes may have been made to this work since it was submitted for publication. The definitive version has been published in Journal of Adolescence, 2011. DOI: 10.1016/j.adolescence.2011.09.005

friendship characteristics. It is also possible that women felt more comfortable sharing stories about their conversations with friends in the context of the group interviews. Future research should further examine potential gendered patterns in interpersonal identity development within friends' interactions.

Although the results of the current study suggest that young adults are indeed participating in substantive interpersonal identity development through their interactions with close same-sex friends, it is important to recognize that the participants did not have an opportunity to explain if and how their friends' feedback impacted their self-perceptions. Furthermore, it is possible that the dating issues friends chose to share with each other (and thus receive feedback about) are constrained and therefore may have a limited impact on interpersonal identity development. For example, Mahmoud (2009) importantly makes the point regarding ethnic identity that interpersonally expressed identities are not necessarily congruent with the intrapersonal identities individuals hold due to limitations on the expression of these identities at both internal and external levels. It is likely that adolescent and young adult interpersonal dating identities endure similar inconsistencies for pragmatic reasons as they navigate through close friendships and dating relationships during this developmental period.

In addition to the numerous factors involved in friends deciding what is and is not shared within the friendship itself, it is important to recognize that the stories participants chose to share, and what was and was not revealed when a story was told, within the interview setting were influenced by the context, including the presence of the interviewer as well as the presence of the other friends. For example, retrospective accounts of conversations narrated by several friends are subject to numerous influences and it is possible that individuals within the group interview setting may inadvertently or consciously misrepresent the effects of a particular interaction with a friend about a dating problem. Furthermore, it is important to recognize that several of the interactions may have solely been the result of prompting within the interview and would not have occurred organically outside of the research setting. These limitations of the present study provide fodder for future research, which could include individual interviews to provide an alternative perspective for assessing meaning-making of past conversations as well as in vivo conversations between friends about current issues.

The selected methodology was also a strength, such that interviews with three close friends offers an effective setting for observing peer conversations about romantic relationships and identity issues. Given the intricate relationship between identity and intimacy in emerging adulthood (Paul \& White, 1990) and that interpersonal interactions catalyze development in both of these areas (Kerpelman, Pittman, \& Lamke, 1997), conversations about problem-talk between friends offer ideal units of analysis. Furthermore, incorporating a third person into a conversation not only allows for a third perspective when recounting past conversations, but also contributes to a more collaborative, and possibly realistic, portrayal of conversational instances of identity development. While additional participants yield more complex interactions that may prove difficult to interpret and understand (as well as obscure individual beliefs not shared by the group), these observations are necessarily more representative of any interactions between friends that contribute to identity processes and offer dynamic in vivo opportunities for assessing interpersonal identity formation.

It is also important to recognize that the generalizability of these results is unknown. There is minimal information previously generated about the active construction of identity within interactions with friends, so the present findings cannot be compared with past results. Future research should continue to explore how conversations between close friends about a variety of topics can foster interpersonal identity exploration and commitment among more diverse samples (for example, with regard to age, education status, and ethnic background). It is likely that the types of responses to dating issues will be different depending on these and other developmental and demographic factors. In particular, it has been noted that while close friendships may take center stage over romantic relationships during adolescence (thus mitigating their potential role in interpersonal identity formation with regard to dating), the shift to privileging romantic relationships during young adulthood (e.g., Barry et al., 2009; Hartup \& Stevens, 1999; Zimmer-Gembeck, 1999) offers a context ripe for development with regard to the domain of dating within interpersonal identity development. As such, conversations within close friendships during adolescence likely influence aspects of interpersonal identity development most relevant to the task of establishing close relationships outside of the family rather than intimate romantic relationships. Furthermore, in extending this research topic to other populations, it would also be useful to hear from individuals about the meaning that their friends' responses have for them, including whether or not they are used to re-evaluate self-perceptions or substantiate pre-existing identity beliefs. It would also be beneficial to include quantitative measures of interpersonal identity formation to supplement further qualitative investigations. 
NOTICE: This is the author's version of a work accepted for publication by Elsevier. Changes resulting from the publishing process, including peer review, editing, corrections, structural formatting and other quality control mechanisms, may not be reflected in this document. Changes may have been made to this work since it was submitted for publication. The definitive version has been published in Journal of Adolescence, 2011. DOI: 10.1016/j.adolescence.2011.09.005

In conclusion, the findings indicate that young adult friends frequently discuss dating issues with each other and that these interactions include patterns of social feedback that both support and challenge the individual's identity beliefs. The interactions identified in the current study suggest that young adults participate in the co-construction of interpersonal dating identities through the social context of close friendships (Adams \& Marshall, 1996; Kerpelman \& Lamke, 1997). The current study also reveals variations in this dynamic process of identity formation through the various ways that friends respond to these issues. Furthermore, there appear to be gender differences in the frequency with which this identity work takes place, with young women describing more interactions than young men. Overall, these findings offer a detailed and nuanced glimpse into young adults' discourse surrounding these developmentally salient issues and speak to the need for further exploration into the interpersonal contexts of identity development. 
NOTICE: This is the author's version of a work accepted for publication by Elsevier. Changes resulting from the publishing process, including peer review, editing, corrections, structural formatting and other quality control mechanisms, may not be reflected in this document. Changes may have been made to this work since it was submitted for publication. The definitive version has been published in Journal of Adolescence, 2011. DOI: 10.1016/j.adolescence.2011.09.005

\section{References}

Adams, G. R., \& Marshall, S. K. (1996). A developmental social psychology of identity: Understanding the personin-context. Journal of Adolescence, 19(5), 429-442. doi:10.1006/jado.1996.0041

Allison, B. N., \& Schultz, J. B. (2001). Interpersonal identity formation during early adolescence. Adolescence, 36(143), 509-523.

Arnett, J. J. (2004). Emerging adulthood: The winding road from the late teens through the twenties. New York: Oxford University Press.

Bamberg, M. (2004). Form and functions of 'slut-bashing' in male identity constructions in 15-year-olds. Human development, 47, 331-353. doi:10.1159/000081036

Bamberg, M. (1997). Positioning between structure and performance. Journal of Narrative and Life History, 7, 335342.

Barry, C., Madsen, S. D., Nelson, L. J., Carroll, J. S., \& Badger, S. (2009). Friendship and romantic relationship qualities in emerging adulthood: Differential associations with identity development and achieved adulthood criteria. Journal of Adult Development, 16, 209-222.

Bartle-Haring, S. (1997). The relationships among parent-adolescent differentiation, sex role orientation and identity development ini late adolescence and early adulthood. Journal of Adolescence, 20(5), 553-565. doi:10.1006/jado.1997.0109

Bartle-Haring, S., \& Strimple, R. (1996). Association of identity and intimacy: An exploration of gender and sexrole orientation. Psychological Reports, 79(3, Pt 2), 1255-1264.

Bartoszuk, K., \& Pittman, J. F. (2010). Profiles of identity exploration and commitment across domains. Journal of Child and Family Studies, 19(4), 444-450. doi:10.1007/s10826-009-9315-5

Braun, V., \& Clarke, V. (2006). Using thematic analysis in psychology. Qualitative Research in Psychology, 3, 77101. doi:10.1191/1478088706qp063oa

Brown, B. B. (1999). “You're going out with who?”: Peer group influences on adolescent romantic relationships. In W. Furman, B. B. Brown, \& C. Feiring (Eds.), The Development of Romantic Relationships in Adolescence (pp. 291-329). New York: Cambridge University Press.

Collins, W. A., \& Madsen, S. D. (2006). Personal relationships in adolescence and early adulthood. In A. L. Vangelisti \& D. Perlman (Eds.), The Cambridge handbook of personal relationships (pp. 191-209). New York: Cambridge University Press.

Connolly, J. A., Furman, W., \& Konarski, R. (2000). The role of peers in the emergence of romantic relationships in adolescence. Child Development, 71, 1395-1408. doi:10.1111/1467-8624.00235

Connolly, J. A., \& Goldberg, A. (1999). Romantic relationships in adolescence: The role of friends and peers in their emergence and development. In W. Furman, B.B. Brown, \& C. Feiring (Eds.), The development of romantic relationships in adolescence (pp. 266-290). New York: Cambridge University Press.

Erikson, E. H. (1968). Identity: Youth and Crisis. Norton, New York.

Feiring, C. (1999). Other-sex friendship networks and the development of romantic relationships in adolescence. Journal of Youth and Adolescence, 28, 495-512. doi:10.1023/A:1021621108890

Grotevant, H. D., \& Adams, G. R. (1984). Development of an objective measure to assess ego identity in adolescence: Validation and replication. Journal of Youth and Adolescence, 13(5), 419-438. doi:10.1007/BF02088639

Grotevant, H. D., Thorbecke, W. L., \& Meyer, M. L. (1982). An extension of Marcia's Identity Status Interview into the interpersonal domain. Journal of Youth and Adolescence, 11(1), 33-47. doi:10.1007/BF01537815

Hartup, W. W., \& Stevens, N. (1999). Friendships and adaptation across the life span. Current Directions in Psychological Science, 8, 76-79. doi:10.1111/1467-8721.00018

Hofer, J., Busch, H., Chasiotis, A., \& Kiessling, F. (2006). Motive Congruence and Interpersonal Identity Status. Journal of Personality, 74(2), 511-542. doi:10.1111/j.1467-6494.2006.00383.x

Kerpelman, J. L., \& Lamke, L. K. (1997). Anticipation of future identities: A control theory approach to identity development within the context of serious dating relationships. Personal Relationships, 4(1), 47-62. doi:10.1111/j.1475-6811.1997.tb00130.x

Kerpelman, J. L., \& Pittman, J. F. (2001). The instability of possible selves: Identity processes within late adolescents' close peer relationships. Journal of Adolescence, 24(4), 491-512. doi:10.1006/jado.2001.0385

Kerpelman, J. L., Pittman, J. F., \& Lamke, L. K. (1997). Toward a microprocess perspective on adolescent identity development: An identity control theory approach. Journal of Adolescent Research, 12(3), 325-346. doi:10.1177/0743554897123002 
NOTICE: This is the author's version of a work accepted for publication by Elsevier. Changes resulting from the publishing process, including peer review, editing, corrections, structural formatting and other quality control mechanisms, may not be reflected in this document. Changes may have been made to this work since it was submitted for publication. The definitive version has been published in Journal of Adolescence, 2011. DOI: 10.1016/j.adolescence.2011.09.005

Korobov, N., \& Thorne, A. (2007). How late-adolescent friends share stories about relationships: The importance of mitigating the seriousness of romantic problems. Journal of Social and Personal Relationships, 24, 971992. doi:10.1177/0265407507084193

Lefkowitz, E. S., Boone, T. L., \& Shearer, C. L. (2004). Communication with best friends about sex-related topics during emerging adulthood. Journal of Youth and Adolescence, 33(4), 339-351. doi:10.1023/B:JOYO.0000032642.27242.c1

Lefkowitz, E. S., \& Gillen, M. M. (2006). "Sex is just a normal part of life”: Sexuality in emerging adulthood. In J. J. Arnett, J. L. Tanner (Eds.), Emerging adults in America: Coming of age in the 21st century (pp. 235256). Washington DC: American Psychological Association.

Lewis, H. L. (2003). Differences in ego identity among college students across age, ethnicity, and gender. Identity: An International Journal of Theory and Research, 3(2), 159-189. doi:10.1207/S1532706XID030205

Mahmoud, H. W. (2009). The role of feeling in intrapersonal and interpersonal ethnic identities. Culture \& Psychology, 15(2), 284-292. doi:10.1177/1354067X09102895

Marcia, J. E. (1966). Development and validation of ego-identity status. Journal of Personality and Social Psychology, 3, 551-558. doi:10.1037/h0023281

Cooper, C. R., \& Grotevant, H. D. (1987). Gender issues in the interface of family experience and adolescents' friendship and dating identity. Journal of Youth and Adolescence, 16, 247-264. doi:10.1007/BF02139093

Meeus, W., Oosterwegel, A., \& Vollebergh, W. (2002). Parental and peer attachment and identity development in adolescence. Journal of Adolescence, 25, 93-106. doi:10.1006/jado.2001.0451

McLean, K., \& Thorne, A. (2003). Late adolescents' self-defining memories about relationships. Developmental Psychology, 39, 635-645. doi:10.1037/0012-1649.39.4.635

Mullis, A. K., Mullis, R. L., Schwartz, S. J., Pease, J. L., \& Michael, S. (2007). Relations among parental divorce, identity status, and coping strategies of college age women. Identity: An International Journal of Theory and Research, 7(2), 137-154.

Ochs, E. \& Capps, L. (2001). Living narrative: creating lives in everyday storytelling. Cambridge, MA: Harvard University Press.

Paul, E. L., \& White, K. M. (1990). The development of intimate relationships in late adolescence. Adolescence, 25(98), 375.

Scharf, M., \& Mayseless, O. (2001). The capacity for romantic intimacy: Exploring the contribution of best friend and marital and parental relationships. Journal of Adolescence, 24, 379-399. doi:10.1006/jado.2001.0405

Schachter, E. P. (2004). Identity configurations: A new perspective on identity formation in contemporary society. Journal of Personality, 72, 167-199. doi:10.1111/j.0022-3506.2004.00260.x

Sprecher, S., \& Felmlee, D. (1992). The influence of parents and friends on the quality and stability of romantic relationships: A three-wave longitudinal investigation. Journal of Marriage \& the Family, 54, 888-900. doi: $10.2307 / 353170$

Sullivan, H. S. (1953). The Interpersonal Theory of Psychiatry. New York: Norton.

Thorbecke, W., \& Grotevant, H. D. (1982). Gender differences in adolescent interpersonal identity formation. Journal of Youth and Adolescence, 11(6), 479-492. doi:10.1007/BF01538808

Thorne, A. (2004). Putting the person into social identity. Human Development, 47, 361-365. doi:10.1159/000081038

Wood, E. Senn, C. Y., Desmarais, S., Park L., \& Verberg, N. (2002). Sources of information about dating and their perceived influence on adolescents. Journal of Adolescent Research, 17, 401-417. doi:10.1177/07458402017004005

Zimmer-Gembeck, M. J. (1999). Stability, change and individual differences in involvement with friends and romantic partners among adolescent females. Journal of Youth and Adolescence, 28, 419-438.

doi:10.1023/A:1021612907073 